\title{
IBOPE E OS DESAFIOS COMPETITIVOS
}

\author{
THE COMPETITIVE CHALLENGES AND IBOPE
}

Recebido em 08.10.2015. Aprovado em 19.06.2017

Avaliado pelo sistema double blind review

DOI: http://dx.doi.org/10.12712/rpca.v11i3.670

\author{
Yákara Vasconcelos Pereira Leite \\ yakarav@gmail.com \\ Universidade Federal Rural do Semi-Árido (UFERSA), Mossoró/RN, BRASIL
}

\section{Walter Fernando Araújo de Moraes}

walter.moraes@ufpe.br

Universidade Federal de Pernambuco (UFPE), Recife/PE, BRASIL

\section{André Gustavo Carvalho Machado}

agcmachado@gmail.com

Universidade Federal da Paraíba (UFPB), João Pessoa/PB, BRASIL

\begin{abstract}
Resumo
Este caso de ensino tem por objetivo conduzir o leitor para o papel de dirigente, e assim, com base na literatura de administração estratégica e/ou negócios internacionais, refletir sobre a realidade vivenciada pelo IBOPE e decidir sobre ações estratégicas para a empresa. Após anos de monopólio no Brasil, a GfK entrou no país, em abril de 2015. Trata-se de uma corporação alemã munida de tecnologia arrojada, experiência e contratos firmados com as principais emissoras nacionais de canal aberto. Devido às características do mercado, dificilmente é possível dividir de forma harmônica o market share com duas grandes corporações. Diante desse cenário, os gestores do IBOPE possuem desafios que precisam ser enfrentados, quais sejam: como manter a empresa brasileira líder de mercado no seu país de origem? Quais estratégias empresariais poderão contribuir no enfrentamento da rival alemã? O caso pode ser utilizado tanto no nível de graduação como de pós-graduação, posterior ou concomitante aos conceitos básicos de Administração Estratégica ou Internacionalização de Empresas. Recomenda-se o uso nas sessões de salas de aula que versem sobre estratégias internacionais, competição, estratégias corporativas, vantagem competitiva e modos de entrada estejam sendo discutidos.
\end{abstract}

Palavras-chave: Caso de ensino. Administração estratégica. Negócios internacionais.

\begin{abstract}
This case of teaching aims to lead the reader to the role of leader, and thus, based on the literature of strategic administration and/or international business, reflect on the reality experienced by IBOPE and decide on strategic actions for the company. After years of monopoly in Brazil, GfK entered the country in April 2015. It is a German corporation equipped with bold technology, experience and contracts signed with the main national broadcasters of open channel. Due to the characteristics of the market, it is difficult to harmonize the market share with two large corporations. Given this scenario, IBOPE managers have challenges that need to be addressed, namely: how to keep the Brazilian company market leader in their country of origin? What business strategies can contribute to the German rival? The case can be used at the undergraduate or postgraduate level, later or concomitantly with the basic concepts of Strategic Management or Internationalization of Companies. It is recommended to use classroom sessions that discuss international strategies, competition, corporate strategies, competitive advantage, and input modes being discussed.
\end{abstract}

Keywords: Entrepreneurship. Market strategies. Marketing. Health plans. Discount cards. 


\section{Introdução}

Um dos propósitos da gestão estratégica empresarial é contribuir para a permanência e crescimento de empreendimentos ativos no mercado. Nesse âmbito, a superação de dificuldades e a exploração de oportunidades devem ser guiadas por ações estratégicas para que as empresas se mantenham competitivas frente aos concorrentes.

$\mathrm{Na}$ atualidade, geralmente as empresas brasileiras enfrentam rivais não apenas do país, mas também os que possuem porte global. Dependendo do setor econômico de atuação, do perfil dos dirigentes, dentre outros fatores, as empresas passam a negociar o seu produto ou serviço em outras nações. Nessa linha, a pesquisa realizada pela Fundação Dom Cabral (FDC, 2012) aponta tendência crescente de investimentos brasileiros no exterior para as empresas se manterem internacionalizadas, destacando-se o Instituto Brasileiro de Opinião Pública e Estatística (IBOPE) como uma corporação de atuação global e líder no Brasil.

O IBOPE está em funcionamento desde 1942 e partiu para a operação no exterior em 1990, época em que passou a aprender e conquistar diferentes mercados. Após anos de aquisição de experiência internacional e detentora de mais de $90 \%$ do market share nacional, a empresa enfrenta a entrada da alemã GfK no Brasil, que vem competindo de maneira agressiva para conquistar o mercado brasileiro. Além do conhecimento técnico (GFK, 2015), a GfK possui 13 mil colaboradores em 100 países e detém tecnologia superior ao IBOPE (GFK, 2017; KUSUMOTO, 2015a).

Diante desse desafio, em um setor que não há espaço para mais de uma empresa atuar no mesmo país, a expectativa é que apenas uma das corporações permaneça no Brasil, tratando-se de "uma briga de morte" (KUSUMOTO, 2015a). O IBOPE talvez esteja vivenciando um dos maiores desafios de sua trajetória. Portanto, este caso de ensino tem como propósito conduzir o leitor para o papel de dirigente, e assim, com base na literatura de administração estratégica e/ou negócios internacionais, poderá refletir sobre a realidade vivenciada pelo IBOPE e decidir sobre a implementação de ações estratégicas para a empresa.

Para tanto, em seguida, o histórico do IBOPE é apresentado com maior enfoque no processo de internacionalização. $\mathrm{Na}$ próxima seção, é possível conhecer alguns planos da GfK para o Brasil e reações do IBOPE frente ao concorrente. A seção com a apresentação das problemáticas antecede as perguntas para discussão, para depois, indicar as notas de ensino, as fontes de obtenção de informações e as referências.

\section{IBOPE e o processo de internacionalização}

O IBOPE atuou em três frentes de negócios, até 2014, quais sejam: IBOPE Media, IBOPE Inteligência e IBOPE Ambiental. O IBOPE Media tinha o objetivo de informar aos meios de comunicação de massa o quanto são ou não prestigiados pela população. $\mathrm{O}$ IBOPE Inteligência se ateve à pesquisa sobre o comportamento humano e o IBOPE Ambiental atuou com serviços voltados ao desenvolvimento de longo prazo, principalmente no que tange aos aspectos ambientais (IBOPE, 2014). No Brasil, dados de fevereiro de 2014 apontam que a corporação possuiu 95\% do market share, sendo a TDI, o seu principal rival na época (Diretora Executiva).

A empresa fundada em 1942, pelo radialista Auricélio Penteado, recebeu a família Montenegro como proprietária, em 1977. Após alguns anos, o processo de internacionalização teve início a partir de 1990. Diante da importância e complexidade, este caso de ensino tem o escopo de retratar a internacionalização da empresa, devido aos ganhos de conhecimento global obtidos. A figura 1 sintetiza a trajetória internacional da corporação que contempla quatro fases e dez eventos marcantes.

Figura 1. Processo de internacionalização do IBOPE

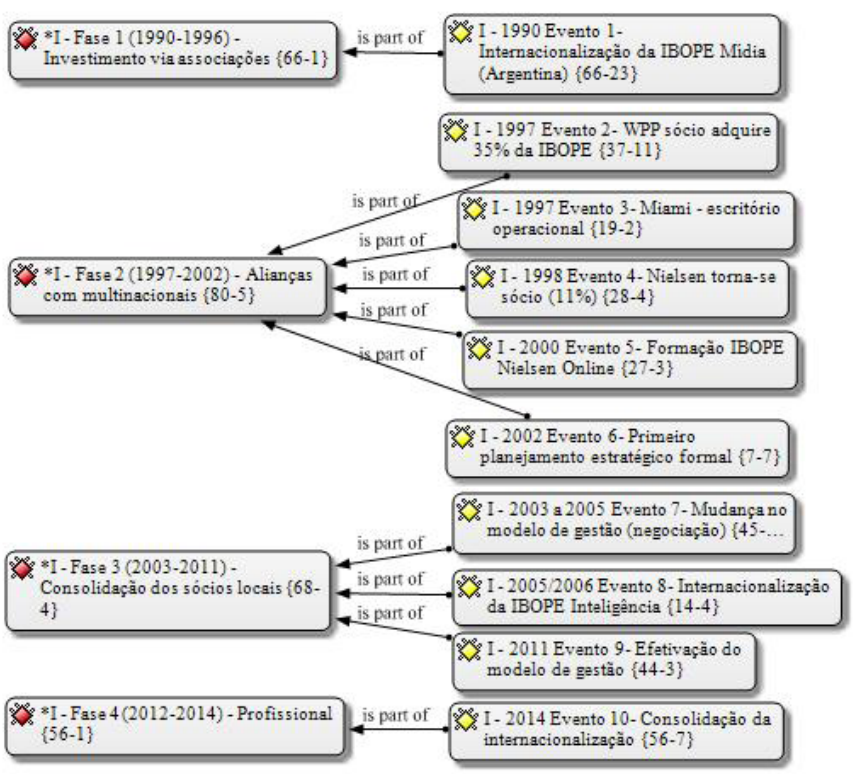

Fonte: Elaboração dos autores no ATLAS.ti (2017). 
A Fase 1, de 1990 a 1996, é determinada pela internacionalização por meio de investimentos via alianças com empresas que atuavam no mesmo setor nos países alvo. O cenário possuía as seguintes características, expõe o Diretor Administrativo:

Vocênão tinhaessa coisamultimídia, multi-plataforma. Você tinha o Brasil, audiência feita pelo IBOPE, na Grã-Bretanha era, na época acho que era TNS. Você olhava o mapa, você tinha na Europa dois, três players, nos Estados Unidos você tinha a Nielsen, a América Latina em meados dos anos 90 estava dividida entre IBOPE e Nielsen e algum player local, e o IBOPE estava percebendo que ou ele crescia para realmente se tornar um player regional importante, ou acabaria [...].

Ao mesmo tempo em que era uma ameaça o cenário competitivo internacional devido à presença de representantes de grande porte, os dirigentes do IBOPE tomaram como uma oportunidade e avançaram pela América Latina, por ter tecnologia diferenciada com o aparelho peoplemeter. A Diretora Executiva explica que: "[...] na década de 90, o IBOPE resolveu, utilizando-se dessa tecnologia e sabendo que ainda não existia essa medição em toda a América Latina, foi então buscar a expansão do mercado na América Latina. Então levou o meter e se juntou a um sócio local". A Argentina foi o primeiro país a receber o IBOPE, a proximidade física e cultura predominaram na decisão dessa escolha. Nessa época, os sócios locais não tinham a tecnologia, apenas o conhecimento do mercado.

$\mathrm{Na}$ Fase 2, entre 1997 e 2002, o IBOPE efetivou alianças com fabricantes multinacionais, a exemplo da Unilever, ao mesmo tempo que manteve o modelo de internacionalização nos países vizinhos com a colaboração de sócios locais. Em 1997, a WPP adquiriu $35 \%$ do IBOPE Media fortalecendo financeiramente a corporação e se posicionando frente a Nielsen.

Em seguida, o IBOPE implementou o único escritório nos EUA apenas com a função de vendas. Em Miami, o escritório tinha o papel de vender informações, por meio de relatórios sobre a América Latina.
No ano de 1998, o IBOPE se torna sócio da Nielsen mediante um acordo estabelecido por 10 anos, o qual a Nielsen possuía 11\% do IBOPE Media. Nessa época, a Nielsen estava em praticamente todos países em que o IBOPE atuava. Assim, pela primeira vez, os representantes da Nielsen e da WPP sentavam juntos com o IBOPE para tomar decisões colaborativas no board. Em 2000, o IBOPE fez outro acordo com a Nielsen para medição de internet.

Essa fase finalizou-se quando a empresa tomou a iniciativa de formalizar o planejamento estratégico com a intervenção de dois consultores para modificar o processo de internacionalização. O propósito estava em se tornar uma companhia global, com identidade bem definida, para ser sustentável competitivamente, no longo prazo.

Entre 2003 a 2011, Fase 3, o mecanismo de expansão foi modificado para crescer adquirindo as empresas sócias dos países vizinhos. A busca para consolidar o planejamento estratégico perdurou até 2011, período de renegociação com as filiais e saída de algumas unidades as quais seus representantes (sócios) não aceitavam a mudança da governança. Além disso, em meados de 2005 e 2006, o IBOPE Inteligência entrou na Argentina, iniciando a internacionalização dessa vertente de negócio.

$\mathrm{Na}$ Fase 4 que engloba 2012 a 2014, o IBOPE alcançou a profissionalização, indicada como uma das ações do planejamento estratégico e a consolidação da governança centralizada. Antes, a operação das unidades internacionais era de responsabilidade do parceiro local, diferentemente desse modelo, a governança passou a ser centralizada no Brasil, com um padrão global. Portanto, a empresa realocou os profissionais em funções mais adequadas aos seus perfis e disseminou uma nova cultura organizacional voltada para a estratégia global.

No aspecto geral, observa-se que a empresa se mostra com habilidade de ser concorrente e acionista ao mesmo tempo, atitude que trouxe vantagens perante a concorrência e permitiu a permanência e crescimento no mercado. Em relação às especificidades desse processo de internacionalização, a figura 2 mostra que a expatriação, a exploração de oportunidades, as parcerias com os anunciantes e sócios locais, a proximidade dos países da América Latina e as redes de relacionamentos foram essenciais.

Devido ao modo de entrada escolhido para iniciar suas operações internacionais, de parcerias com 
empresas locais dos países alvo, o IBOPE enviava, em menor quantidade, brasileiros para trabalhar nas diversas operações. $\mathrm{Na}$ atualidade, com a concepção de corporação globalizada, o fluxo de expatriados aumentou. Sobre o assunto, a Diretora Executiva explicou que existem oportunidades, mas o envio para outros países depende do talento das pessoas.

Quanto à exploração de oportunidades, as alianças estratégicas possibilitaram a concepção de redes de relacionamentos permitindo a identificação de oportunidades. Os dirigentes identificaram oportunidades advindas da estratégia de cooperação. Para os gestores do IBOPE, as alianças estratégicas foram a força motriz da sua expansão e por isso, mesmo com a mudança na governança, a empresa continua a firmar parcerias com as corporações internacionais de maior porte, sejam elas rivais ou clientes (anunciantes).

Figura 2 . Aspectos do processo da internacionalização do IBOPE

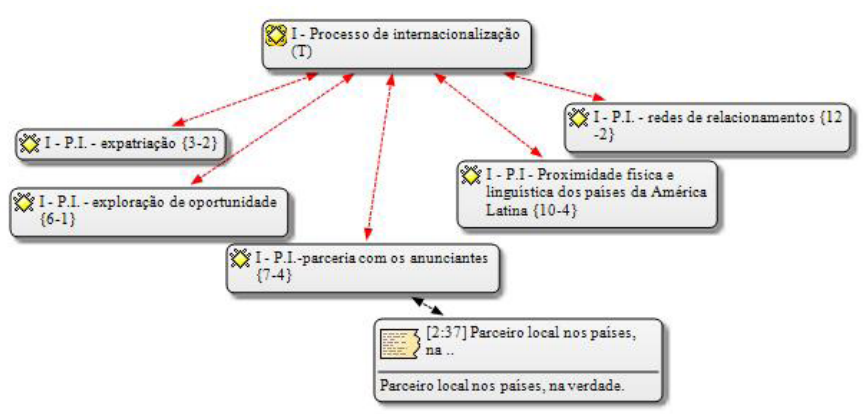

Fonte: Elaboração dos autores no ATLAS.ti (2017).

É marcante o posicionamento do IBOPE ao definir o escopo de atuações em países próximos física e culturalmente. A maior parte do trabalho esteve voltada para os países da América Latina e apenas conseguiu abrir um escritório de vendas nos EUA, exatamente na cidade mais latina do país que é Miami.

\section{Estratégias empresariais implementadas}

Dentre as estratégias adotadas pelo IBOPE na internacionalização, a aliança estratégica e a aquisição são predominantes (ver figura 3). A coopetição, por ser uma estratégia de competição que possui cooperação, está atrelada à aliança estratégica.
Figura 3 . Estratégias adotadas na internacionalização do IBOPE

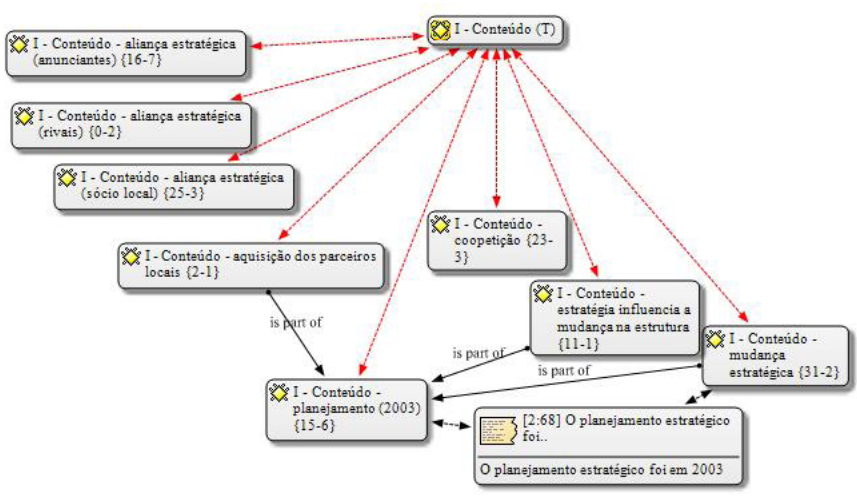

Fonte: Elaboração dos autores no ATLAS.ti (2017).

As alianças horizontais (com os concorrentes) e com outros parceiros mostram-se essenciais para o IBOPE. As horizontais foram representadas por rivais de grande porte e por sócios locais. Dentre as maiores do segmento, o IBOPE tornou-se sócio da WPP para se fortalecer financeiramente e da Nielsen. Anterior a essa sociedade, a entrada nos países da América do Sul foi viabilizada pela parceria com os sócios locais que detinham conhecimento de mercado. O IBOPE fazia a negociação para ser majoritário, entrava com a tecnologia (aparelho meter) e juntava-se, adquirindo conhecimento do parceiro, para se expandir no país. A coopetição sempre esteve presente nas ações empresariais do IBOPE que conseguiu ser parceiro e concorrente simultaneamente dos rivais.

No eixo de alianças com outras empresas, identificamse os anunciantes, que embora não sejam clientes diretos, são os maiores interessados. Para eles, os serviços do IBOPE formam a métrica de mercado que baliza em algum grau a sua tomada de decisão e serve de parâmetro para garantir o acompanhamento da alocação dos recursos. A parceria com a Unilever favoreceu a entrada em países da América Latina, isso porque as multinacionais possuem essa necessidade e cobram dos canais os índices.

As aquisições se concentram numa etapa mais recente representada por um movimento inverso ao adotado no início da internacionalização. O IBOPE avança para adquirir os sócios locais na busca de agilidade, consolidação e sinergia para se tornar uma empresa mais globalizada. A estratégia de aquisição fez parte do passo inicial indicado no primeiro planejamento estratégico formal da empresa. 
Embora o primeiro planejamento estratégico formal date do ano de 2003, as estratégias implementadas antes desse tempo foram planejadas pelos gestores. A intenção estratégica sempre esteve assegurada no objetivo de se tornar um player forte na América Latina (Diretor Administrativo).

A implementação das ações contempladas no planejamento estratégico com as aquisições e busca de sinergia e profissionalização para se tornar uma empresa com uma cultura organizacional definida influenciou a estrutura organizacional. O replanejamento estrutural contou com as mudanças de cargos e funções, as unidades estrangeiras deixaram de ter autonomia plena, a corporação adotou a estrutura matricial com unidades de negócios, com a presença dos gestores regionais.

Nessa etapa, a mudança estratégica influenciou a operação internacional da empresa que foi reconhecida como complexa. Para iniciar a sua execução, foram necessários dois anos de preparo da equipe para conceber a holding. A mudança teve como pano de fundo indicar aos funcionários que o pensamento passara de nacional para ser responsável pela América Latina.

\section{A entrada da GfK no Brasil e a reação do IBOPE}

Inicialmente, é importante apresentar a concorrente multinacional que chegou para disputar o mercado brasileiro com o IBOPE. A GfK é responsável pelo nascimento da pesquisa de mercado institucional na Alemanha, fundada pelo professor Wilhelm Vershofen, com sede em Nuremberg, em 1934 (GFK, 2015).

$\mathrm{Na}$ década de 60, a empresa iniciou a expansão internacional. Em 1990, a GfK se tornou uma empresa de sociedade anônima e no ano de 1999, a corporação conquistou a presença em 37 países. A aquisição da NOP World ocorreu em 2005, passando a incluir 47 empresas e mais de 1.500 colaboradores. Nessa etapa, a companhia se tornou uma das cinco maiores e bem sucedidas corporações de pesquisa de mercado do mundo. $\mathrm{Na}$ atualidade, com mais de 13 mil colaboradores em mais de 100 países, a GfK entrou no Brasil para competir e vencer a empresa brasileira IBOPE, desde 2015 (GFK, 2017).

Em entrevista, o então diretor geral no Brasil da GfK,
Ricardo Monteiro, explicou que a empresa:

[...] está trazendo para o Brasil uma tecnologia desenvolvida na Suíça para enviar informações dos televisores a cada dois segundos para uma central, à qual caberá compilar os dados. O volume de informações é trinta vezes maior que o dos aparelhos do IBOPE, que enviam dados minuto a minuto (KUSUMOTO, 2015a).

No mês de abril de 2015, a GfK estreou no mercado brasileiro de medição de TV aberta e paga, atacando o monopólio do IBOPE. "A meta para 2015 é conquistar 250 clientes e chegar a 600 em 2016, entre emissoras de televisão, anunciantes e agências de publicidade". Desde novembro de 2013 que o SBT, Record, RedeTV e Band firmaram contrato com a GfK para financiar o serviço nos próximos quatro anos, atingindo uma média de $\mathrm{R} \$ 100$ mil na negociação com esses clientes (MEYGE, 2014). Em relação à adesão da Rede Globo, Ricardo Monteiro explica:

É a emissora que mais faz pesquisa no Brasil e tem um histórico com o nosso concorrente de muito tempo. Eles só vão trocar quando sentirem que não dá mais para ficar com o anterior. A Globo vai avaliar primeiro se vale a pena ou não, vai querer um estudo com mais detalhes, esperar os nossos resultados (KUSUMOTO, 2015b).

No primeiro mês de operação (abril de 2015), a medição foi realizada na Grande São Paulo e no Rio de Janeiro, para em seguida mensurar outras regiões metropolitanas (MEYGE, 2014). Além disso, o diretor geral revelou que o serviço prestado é diferenciado:

Vamos trazer um equipamento
que transmite informação de
dois em dois segundos e uma
tecnologia baseada no áudio,
capaz de diferenciar até mesmo
programas iguais exibidos em
emissoras diferentes, como o
horário eleitoral. (Um peoplemeter


parecido, que funciona a partir do reconhecimento de áudio, passou a ser usado pelo Ibope em maio de 2013. Atualmente, o instituto estima que ele está instalado em $30 \%$ dos domićlíos de sua amostra no Brasil). A empresa está para terminar um novo levantamento socioeconômico, um censo, que mostra a distribuição da população. Esse estudo foi essencial para que a GfK montasse seu painel, que será formado por cerca de 7.000 domicílios, frente ao de pouco mais de 5.000 usado para a medição do Ibope. A nossa medição também será superior em qualidade, já que vamos conseguir acompanhar as atividades de cada indivíduo da casa, da classe A à E. Vamos estar até em favelas. (Segundo Dora Câmara, diretora regional para o Brasil do Ibope Media, a empresa tem aparelhos de medição de audiência em casas de todas as classes sociais, inclusive em residências que apresentam condições sociais similares às de casas em favelas) (KUSUMOTO, 2015b).

Acostumados com o monopólio, os dirigentes do IBOPE, desde o início de 2015, enfrentam esse desafio, sobretudo por ter um rival determinado a ocupar o espaço no seu país de origem. Frente a esse cenário, a empresa vem agindo para manter-se na liderança de mercado. A ampliação do universo de pesquisa para 5.280 domicílios e cobertura de televisão por assinatura, que passou de nove praças para 15, fazendo a apuração unificada dos índices, é uma das novas ações (MEYGE, 2014). Além disso, "[...] está nos planos da empresa brasileira a medição de audiência de conteúdo assistido sob demanda por operadoras de televisão por assinatura e o monitoramento de dispositivos móveis (tablets e celulares)" (KUSUMOTO, 2015b).

A atitude do IBOPE demonstra que os dirigentes da corporação estão preocupados com a entrada do rival no país. Espera-se por um duelo histórico entre duas grandes potências internacionais que talvez comprometa a existência da brasileira IBOPE.

\section{Problemática}

No segundo semestre de 2014, a divisão IBOPE Media foi adquirida pela concorrente britânico WPP, tornando-se a Kantar IBOPE Media. Da originária IBOPE, permaneceu a IBOPE Inteligência com direção brasileira que atua há mais de sete décadas com monitoração e medição na América Latina e realiza pesquisa de intenção de voto (GLOBO, 2014; IBOPE INTELIGÊNCIA, 2017).

Em relação à britânica, destaca-se que:

A Kantar é o braço do Grupo
WPP responsável por gestão de
informação e uma das maiores
empresas de pesquisa, insight e
consultoria do mundo. Por meio
da união dos diversos talentos
de suas 12 empresas especialistas
em seus segmentos, a Kantar é
a mais relevante fornecedora de
informações e insights, que inspira
e motiva a comunidade mundial
de negócios (KANTAR IBOPE
MEDIA, 2014).

Nos últimos anos, a Kantar expandiu sua cobertura global e adquiriu novas capacidades de medição por meio de aquisição de empresas, como a Data Republic, a Precise, a unidade de audio watermarking da Civolution, bem como a recentemente anunciada troca de ativos e investimentos na Rentrak, especialista em medição de TV e vídeo nos Estados Unidos (KANTAR IBOPE MEDIA, 2014). É importante destacar que:

A marca Ibope Media, fundada no Brasil há 72 anos, será mantida, assim como toda a atual diretoria da empresa. Orlando Lopes, atua CEO do Ibope, permanecerá no comando da empresa e passará a fazer parte do conselho da Kantar Media, reportando-se ao presidente e CEO da Kantar Media, Andy Brown (GLOBO, 2014).

$\mathrm{Na}$ atualidade, a disputa do mercado brasileiro da GfK acontece com a Kantar IBOPE Media. Enquanto a 
GfK foi a primeira a prestar serviços de pesquisa de mercado institucional na Alemanha, país de origem, de modo semelhante, o IBOPE lançou os serviços de medição de audiência no Brasil.

De forma estratégica, a GfK entrou no país com a vantagem de ter contratos fechados com um número considerável de emissoras de TV. A empresa antes de iniciar a medição, realizou um censo da população brasileira finalizado em dezembro de 2014 (KUSUMOTO, 2015a). Além disso, desde sua chegada, intencionou firmar contrato com a Rede Globo e para isso fez investidas comerciais junto à emissora (MEYGE, 2014). Como resultado desse esforço, desde o primeiro semestre de 2017, a Rede Globo começou a avaliar os serviços da GfK (NEVES, 2017). Esse movimento comercial pode colocar em risco o acordo comercial existente entre o IBOPE e a Globo que perdura há anos.

Outro fator a ser considerado é que se houver o enfraquecimento da Kantar IBOPE Media no mercado brasileiro, por meio da perda de clientes para a rival, isso poderá comprometer a operação no exterior, especialmente devido ao formato de governança corporativa em vigor. Portanto, diante da complexidade existente, é possível levantar alguns questionamentos iniciais para reflexão: como os dirigentes da Kantar IBOPE Media conseguirão manter a divisão brasileira na liderança de mercado? Quais estratégias empresariais poderão contribuir no enfrentamento da rival alemã?

\section{Notas de Ensino}

\section{Objetivos educacionais}

O caso explora situações que podem ser compreendidas a partir de teorias, modelos e práticas de estratégia empresarial, incluindo a Visão Baseada em Recursos e Organização Industrial, Modelo Diamante (Determinantes da Vantagem Competitiva Nacional), Modelo das 5 forças competitivas e Modelo SWOT. Além disso, são abordados assuntos amplamente discutidos pela literatura, tais como: processo de internacionalização; modos de entrada no mercado internacional; governança corporativa, influência dos contextos interno e externo para a mudança e conteúdo das estratégias e riscos associados.

Nesse contexto, os objetivos principais da aplicação do caso são:
- Conduzir os alunos à avaliação e discussão das principais estratégias adotadas pelo IBOPE (BARNEY, 2002; BARNEY; HESTERLY, 2007; DE WIT; MEYER, 2004; PORTER, 1989, 1999);

- Relacionar o embasamento teórico às ações desenvolvidas pela empresa em foco, e fazer com que os alunos sejam capazes de discernir e tomar decisões sobre a administração estratégica (BARNEY, 1991, 2002; PENROSE, 2006; PETERAF, 1993; PORTER, 1999; WERNERFELT, 1984) e o processo de internacionalização de empresa (ANDERSSON, 2000; CARNEIRO; DIB, 2007; JOHANSON; VAHLNE, 1977, 2009; LEITE, MORAES, 2014; MELIN, 1992; PORTER, 1989; VERNON, 1966).

\section{Utilização recomendada}

O caso pode ser utilizado tanto no nível de graduação como de pós-graduação, posterior ou concomitante aos conceitos básicos de Administração Estratégica ou Internacionalização de Empresas. Recomendase o uso, especialmente, em sessões que estratégias internacionais, competição, estratégias corporativas, vantagem competitiva e modos de entrada estejam sendo discutidos. Nesse sentido, sugere-se sua adoção em disciplinas do curso de administração, tais como, mas não apenas sobre Estratégia Empresarial, Administração Estratégica, Estratégias de Internacionalização, Negócios Internacionais.

\section{Fonte de obtenção de dados}

Os dados que fundamentam a elaboração deste caso de ensino foram coletados em fontes bibliográficas e por meio de entrevistas realizadas com o Diretor de Administração e a Diretora Executiva do IBOPE, na sede da empresa localizada na cidade de São Paulo-SP, no primeiro semestre de 2014. Quanto às fontes bibliográficas, o site da empresa, a Revista Valor Econômico, algumas publicações acadêmicas (MARCENES, 2009; REIS, 2012), dentre outros serviram como fonte secundária. Ademais, o software ATLAS.ti contribuiu na análise dos dados qualitativos e disposição das redes apresentadas ao longo do texto.

\section{Questões para discussão}

a) Identifique e explique quais forças de Porter estão presentes no caso do IBOPE.

b) Apresente os recursos competitivos do IBOPE e da GfK e analise como cada um deles atende ao modelo VRIO. 
c) Qual foi o modo de entrada escolhido pelo IBOPE para se internacionalizar? Quais motivos levaram a essa escolha?

d) Com base no Diamante de Porter, relate se o IBOPE é capaz de continuar competindo com empresas de outros países considerando a situação de perda da liderança de mercado no Brasil.

e) Existem vantagens em ser o primeiro a entrar numa indústria? Explique se o IBOPE obteve algum benefício por estar na vanguarda da medição de audiência no mercado brasileiro.

f) Elabore a análise SWOT do caso IBOPE.

g) A distância psíquica foi determinante no processo de internacionalização? Por quê?

h) A corporação brasileira possui alguma vantagem competitiva? Por quê?

i) No lugar dos dirigentes, qual seria o seu plano e ações para continuar o processo de internacionalização?

\section{Referências}

ANDERSSON, S. The Internationalization of the firm from an entrepreneurial perspective. International Studies of Management \& Organization, v. 30, n. 1, p. 63-92, Spring 2000.

BARNEY, J. B. Firm resources and sustained competitive advantage. Journal of Management, $\mathrm{v}$. 17, n. 1, p. 99-120, 1991.

BARNEY, Jay B. Gaining and sustaining competitive advantage. 3. ed. New Jersey: PrenticeHall, 2002.

BARNEY, Jay B.; HESTERLY, William S. Administração estratégica e vantagem competitiva. São Paulo: Pearson Pretince Hall, 2007.

CARNEIRO, Jorge; DIB, Luís Antônio. Avaliação comparativa do escopo descritivo e explanatório dos principais modelos de internacionalização de empresas. INTERNEXT- Revista Eletrônica de Negócios Internacionais da ESPM, São Paulo, v.2, n.1, p.1-25, jan./jun. 2007.

DE WIT, Bob; MEYER, Ron. Strategy: process, content, context. 3. ed. London: Thomson, 2004.
FDC. Ranking das Transnacionais Brasileiras 2011: crescimento e gestão sustentável no exterior. Belo Horizonte: FDC, 2012.

GFK. História da empresa. Disponível em: <http://www.gfk.com/br/about-us/companyhistory/Paginas/default.aspx > . Acesso em: 20 março 2015.

GFK. Sobre GfK. 2017. Disponível em: < http:// www.gfk.com/pt-br/sobre-a-gfk/overview/>.

Acesso em: 04 jul. 2017.

GLOBO. Kantar, do grupo WPP, adquire controle do Ibope Media. 2014.

Disponível em: < http://g1.globo.com/economia/ midia-e-marketing/noticia/2014/12/kantar-dogrupo-wpp-adquire-controle-do-ibope-media.html>. Acesso em: 04 jul. 2017.

IBOPE. Quem somos. Disponível em: <http:/ / www.ibope.com.br/pt-br/ibope/quemsomos/ Paginas/default.aspx 2014>. Acesso em: 21 nov. 2014.

IBOPE INTELIGÊNCIA. Institucional. 2017. Disponível em: < http://www.ibopeinteligencia. $\mathrm{com} /$ institucional/ibope-inteligencia/ > . Acesso em: 04 jul. 2017.

JOHANSON, J; VAHLNE, Jan-Erik. The internationalization process of the firm - a model of knowledge development and increasing foreign markets commitments. Journal of International Business Studies, Spring, p. 23-32, 1977.

JOHANSON, Jan; VAHLNE, Jan-Erik. The Uppsala Internationalization Process Model Revisited: from liability of foreignness to liability of outsidership. Journal of International Business Studies, n. 40, p. 1411-1431, 2009.

KANTAR IBOPE MEDIA. Kantar anuncia aquisição do controle do IBOPE Media, líder em medição de mídia e investimento publicitário na América Latina. 2014. Disponível em: < https://www.kantaribopemedia.com/kantar-anunciaaquisicao-do-controle-do-ibope-media-lider-emmedicao-de-midia-e-investimento-publicitario-naamerica-latina/>. Acesso em: 04 jul. 2017.

KUSUMOTO, Meire. Ibope ganha rival GfK e 2015 deve ter guerra da audiência. Veja.com. 2015a. Disponível em: <http://veja.abril.com.br/ 
noticia/entretenimento/ibope-ganha-rival-gfk-e2015-deve-ter-guerra-da-audiencia/ >. Acesso em: 19 março 2015.

KUSUMOTO, Meire. GfK planeja medir audiência até de Netflix e YouTube. Veja.com. 2015b. Disponível em: < http://veja.abril.com. $\mathrm{br} /$ noticia/entretenimento/confira-a-integra-daentrevista-com-ricardo-monteiro-da-gfk $>$. Acesso em: 19 março 2015.

LEITE, Y. V. P.; MORAES, W. F. A. de. Facetas do Risco no Empreendedorismo Internacional, Revista de Administração Contemporânea - RAC, Rio de Janeiro, v. 18, n. 1, p. 96-117, Jan./Fev., 2014.

MARCENES, L. H. de. Estratégias de internacionalização: investimentos diretos externos de multinacionais brasileiras. Dissertação (Mestrado em Gestão Empresarial) - Escola Brasileira de Administração Pública e de Empresas da Faculdade de Administração da Fundação Getúlio Vargas.

Programa de Mestrado em Gestão Empresarial. Rio de Janeiro, 2009.

MELIN, Leif. Internationalization as a strategy process. Strategic Management Journal, 13, 1992. p. $99-118$.

MEYGE, Adriana. Com contrato com emissoras, GfK estreia em 2015. Valor Econômico.

Disponível em: < http://www.valor.com.br/ empresas/3828318/com-contrato-com-emissorasgfk-estreia-em-2015>. Acesso em: 20 março 2015.

NEVES, Ernesto. Globo avalia serviços da GFK, concorrente do Ibope. 2017. Disponível em: < http:/ / veja.abril.com.br/blog/radar-on-line/globo-avaliaservicos-da-gfk-concorrente-do-ibope/>. Acesso em: 04 jul. 2017.

PENROSE, E. A teoria do crescimento da firma. Campinas-SP: Editora da Unicamp, 2006.

PETERAF, M. A. The cornerstones of competitive advantage: a resource-based view.

Strategic Management Journal, v. 14, n. 3, p. 179188, 1993.

PORTER, M. E. A Vantagem competitiva das nações. Rio Janeiro: Campus, 1989.

PORTER, M. E. Competição: Estratégias Competitivas Essenciais. 6. ed. Rio de Janeiro: Campus, 1999.
REIS, A. M. A relação entre estratégia e estrutura no processo de internacionalização de empresas multinacionais brasileiras. 136f. Dissertação (mestrado) - Escola de Administração de Empresas de São Paulo: Fundação Getúlio Vargas, 2012.

WERNERFELT, B. A resource-based view of the firm. Strategic Management Journal, v. 5, p. 171180, 1984.

VERNON, Raymond. International investment and international trade in the product cycle. Quarterly Journal of Economics, v. 80, n. 2, p. 191-207, 1966. 